\title{
Study on Students' Emotion based on Kansei Engineering in E-Learning
}

\author{
Yunyun Wei ${ }^{1, a}$, Wansong Tong ${ }^{1, b}$ and Xiangran Sun ${ }^{2, c}$ \\ ${ }^{1}$ School of Architecture and Design, Beijing Jiaotong University, Beijing, China \\ ${ }^{2}$ Information Engineering School, Communication University of China, Beijing, China \\ ayunyunwei@outlook.com, b14314025@bjtu.edu.cn, csunxrcuc@cuc.edu.cn
}

\begin{abstract}
Keywords: E-Learning; Students' emotion; Kansei engineering; Similarity measure
\end{abstract}
\begin{abstract}
E-learning is becoming more and more popular, which is a kind of learning mode based on network, with the dramatic development of computer and network technology. Although e-learning system is bringing about an education revolution, the lack of emotion and interactivity always persecute students and researchers. In this paper, a system architecture based on e-learning is proposed, which focused on interaction. In order to prompt students' experience of learning, we analyze the relationship of students' emotion and teaching content based on Kansei Engineering. A novel approach is proposed to evaluate students' emotion to teaching content, which can improve students' learning efficiency.
\end{abstract}

\section{Introduction}

With the rapid growth of information technology, an education revolution is expanding in the whole world. Depending on state-of-the-art computer and network technologies, modern education achieves significant progresses towards traditional education. E-learning is a kind of mode education mode, which is becoming more and more popular [1]. The development of e-learning has brought new trends and opportunities to improve the education quality and increase the learning efficiency.

Emotion is fundamental to human experience, cognition and activities such as learning, communication, and rational decision-making. Lots of researches conclude that emotions influence the results of students' learning. It is obvious that students in different majors will express different emotions towards a same teaching content. So emotion recognition and emotion management should be an essential and major function in e-learning system, which could promote a more efficient and interactive teaching and learning. Students' learning experience is the core of e-learning system. In order to meet user requirements and promote user experience, many methods has been developed based on user mental model. Kansei Engineering [2] is one of the approaches and used wildly, which was founded by Mitsuo Nagamachi in 1970. It is capable of evaluating different feelings and emotions and presents their relationship with the productions. But it is not well known that the measurement of students' emotion is performed based on Kansei Engineering in the field of e-learning. Cloud Computing is applied to everywhere nowadays such as web-service, e-commerce, education. The learning system based on cloud computing platform not only can record learning inhabits and experience for each student, but also can support teachers to design interactive instructions and improve the teaching results.

The aim of this research is to investigate the relationship students' emotion to teaching content based on e-learning system and to propose an approach of evaluation students' feelings to the contents in different majors. The results of the research can help teachers improving their teaching ways, then prompt user experience of e-learning system. The rest of this paper is organized as follows: Students' emotion are introduced and a new e-learning system is presented in the second section; then it describes the measurement method based on Kansei Engineering in our research; in the fourth section, we figure out the statistical analysis of students' emotion to teaching content; finally, it is the conclusion and perspective of future work. 


\section{Students' Emotion and E-Learning System}

Students' Emotion and Teaching Content. It is a major challenge that teaching is not only how to gain students' attention but also how to protect them against negative emotions such as disgust, boredom and self-abasement in e-learning. Generally speaking, teaching contents promote the efficiency of education and develop the technique of students in many ways such as interactive multimedia, digital game and activities. Teachers can use different contents to influence and manage students' emotions and even enhance the learning efficiency of students. The interactive multimedia acts as a tool for cognitive, it can stimulate students to study new topics and help students to understand knowledge quickly. And it also can promote students to cooperate and discuss in the learning process. Digital game based education used for educational purposes can engage the students by fun interactive learning methods, and make students learning more easily and not in a boring matter. It can not only enhance the interaction in teaching and learning process, but also effect students' emotions prominently. Activities can make teaching and learning such variety, which integrate cooperation tasks and competitive elements to stimulate student's learning motivation. On the basis of the content, activities in classroom include problem solution and task competition. It turns out that choices of activities and the implementation is a prominent way to influence students' emotions.

Emotion Management of E-Learning System. To prompt the efficiency of teaching and learning of e-learning, we designed an interaction system based on emotion management, which is centered on cloud computing platform. The architecture of our proposed system is shown in Fig. 1. It includes three key parts: the cloud computing platform, the teacher's terminal and the student's terminal. Cloud platform is the core of the e-learning system and connects to both the teacher's terminal and the student's terminal, which is the computation and management center based on management of students' emotion. The e-learning system has three key technologies: decision-support system, emotion management and content management. Cloud computing platform collects each student's learning experience and status, and analyzes the characteristics of each student. It can help e-learning system to make perfect decision for the teacher. Depending on cloud computing platform, students' emotions are computed precisely and teaching contents are delivered according to teachers' plans and students' requirements.

\section{Research Method based on Kansei Engineering}

Kansei Engineering is a classical and modern technology focused on users' feelings, which is a simple cognitive method to connect the favorite product or services with the expected emotions. After Kansei Engineering was introduced to the field of product design, emotions can be measured using self-report instruments and various self-report channels from the user. Kansei Engineering is gaining widespread popularity in research institutions, measuring emotions are very unique and the findings vary from one domain of research to another.

In our research, a student's emotions were studied using a self-reporting questionnaire survey to collect the required data. The questionnaire used the SD 5-Point Scale [3] to measure the emotions of the respondents. We extracted 12 emotions derived from PrEmo [4]. The emotions can be classified into two categories which are the positive emotions and negative emotions. The positive emotions consist of desire, satisfaction, hope, fascination, pride and joy. Alternatively, the negative emotions consist of disgust, dissatisfaction, fear, shame, boredom and sadness. These are primary emotions and it is easily understood by the undergraduate students in different majors. The selected 12 emotions were explained with text to facilitate Kansei evaluation. At the same time, we also presented the weight factor corresponding to each emotion in order to calculate the influence of emotion shown in Table 1. 
Table 1 Students' emotion and weight factor

\begin{tabular}{|c|c|c|c|c|c|c|c|c|c|c|c|c|}
\hline 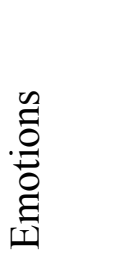 & $\begin{array}{l}\stackrel{\mathscr{\Xi}}{\mathscr{N}} \\
\stackrel{\leftrightarrow}{0}\end{array}$ & 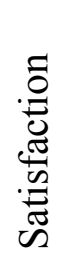 & 茴 & 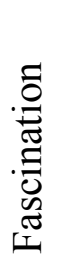 & $\frac{0}{2}$ & ટ્م & 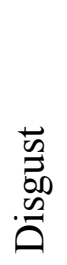 & 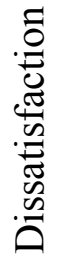 & $\begin{array}{l}\underset{\Xi}{\tilde{\Xi}} \\
\text { ज्ञ }\end{array}$ & 节 & 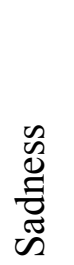 & 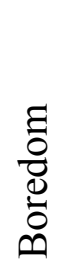 \\
\hline $\begin{array}{l}\text { Weight } \\
\text { Factor }\end{array}$ & 2 & 4 & 1 & 5 & 2 & 3 & 1 & 2 & 4 & 5 & 3 & 2 \\
\hline
\end{tabular}

The specimens were used in our experiment are the contents used in e-learning system, including multimedia, game and activities, which are denoted by $\mathrm{C} 1, \mathrm{C} 2, \mathrm{C} 3$. There were 15 selected contents provided to the group of respondents by e-learning system. There were two parts in the questionnaire: the respondents' personal information and the evaluations of their emotions. The item in the first part is some information of respondents including gender, age, major, grade and so on. In the second part, the Kansei evaluations are given by those respondents about the emotions. The respondents should respond to a series of open ended questions, in order to state the emotions reflected by the contents and rate the emotions accordingly.

The respondents for this research consist of 60 undergraduate students, which are from two different majors: Science Major and Arts Major. They were selected based on their computer literacy and e-learning experience. The selection criteria for the respondents are that the students are required to have e-learning experience. Firstly, we divided the Kansei evaluation respondents into 2 groups: one is Science Major Group (30 students), the other is Arts Major Group (30 students). Two Kansei evaluation sessions were held separately in the different computer labs. Each Kansei evaluation session is approximately 1 hour course including multimedia, game and activities based on e-learning system. The respondents were then asked to rate their emotions and classify the contents into the list using the self-reporting online questionnaire. Secondly, the process of data analysis is to calculate the mean value for each emotion using the descriptive statistics by all collected data from the self-reporting questionnaire. The statistical results are listed in Table 2.

Table 2 Emotion evaluation of students

\begin{tabular}{|c|c|c|c|c|c|c|c|c|c|c|c|c|c|}
\hline 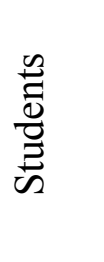 & 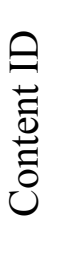 & $\begin{array}{l}\stackrel{\mathscr{\Xi}}{\mathscr{U}} \\
\stackrel{\mathscr{D}}{0}\end{array}$ & 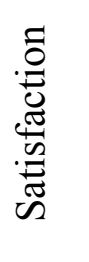 & 苋 & 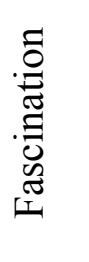 & $\frac{0}{2}$ & $\stackrel{\overrightarrow{0}}{\circ}$ & 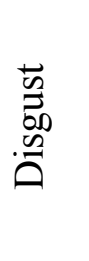 & 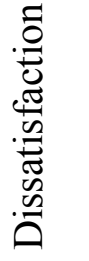 & $\begin{array}{c}\stackrel{\Xi}{\Xi} \\
\underset{\tilde{\Xi}}{\tilde{U}}\end{array}$ & 胥 & 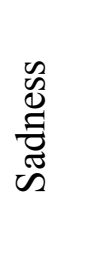 & 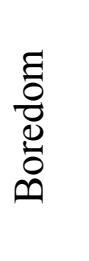 \\
\hline \multirow{3}{*}{$\frac{\dot{d}}{\delta} 8$} & $\mathrm{C} 1$ & 3.35 & 4.16 & 4.11 & 4.13 & 2.35 & 3.35 & 1.05 & 1.21 & 1.10 & 1.03 & 1.22 & 1.94 \\
\hline & $\mathrm{C} 2$ & 3.78 & 4.51 & 4.22 & 4.33 & 2.41 & 3.87 & 1.27 & 1.24 & 1.07 & 1.07 & 1.35 & 1.43 \\
\hline & $\mathrm{C} 3$ & 3.26 & 4.22 & 3.97 & 4.01 & 2.17 & 3.03 & 1.21 & 1.28 & 1.11 & 1.09 & 1.34 & 1.78 \\
\hline \multirow{3}{*}{ 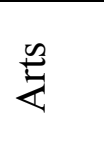 } & $\mathrm{C} 1$ & 3.23 & 4.38 & 4.21 & 4.27 & 2.31 & 3.38 & 1.07 & 1.23 & 1.01 & 1.04 & 1.22 & 1.83 \\
\hline & $\mathrm{C} 2$ & 3.50 & 4.42 & 4.23 & 4.33 & 2.51 & 3.51 & 1.22 & 1.26 & 1.09 & 1.07 & 1.32 & 1.56 \\
\hline & C3 & 3.58 & 4.62 & 4.33 & 4.45 & 2.58 & 3.78 & 1.26 & 1.24 & 1.07 & 1.07 & 1.35 & 1.43 \\
\hline
\end{tabular}

\section{Analysis Using Similarity Measure}

In several similarity metrics to calculate similarity, we select Pearson Correlation Coefficient to perform Similarity Measure. Pearson Correlation Coefficient [5] is a statistical measurement of linear Correlation between two variables. 


$$
r=\frac{\sum_{i=1}^{n}\left(x_{i}-\bar{x}\right)\left(y_{i}-\bar{y}\right)}{\sqrt{\sum_{i=1}^{n}\left(x_{i}-\bar{x}\right)^{2}} \sqrt{\sum_{i=1}^{n}\left(y_{i}-\bar{y}\right)^{2}}} .
$$

Here let ${ }^{X_{i}}$ be the weight factor of students' emotions and ${ }^{y_{i}}$ be the value of emotion evaluation of students. $\bar{x}$ denotes the mean value of the weight factors of students' emotions, $\bar{y}$ denotes the mean value of emotion evaluation of students and $n$ represents 6 positive emotions and 6 negative emotions. $r$ is the similarity between two variables. We classify the students' emotion into two parts: positive emotion and negative emotion and calculate two set of PCC for science students and arts students. The computed results are listed in Table 3.

Table 3 Emotion measure of different major students towards teaching contents

\begin{tabular}{|c|c|c|c|}
\hline Emotion & Content ID & Science Major & Arts Major \\
\hline \multirow{3}{*}{ Positive Emotion } & $\mathrm{C} 1$ & 0.396 & 0.435 \\
\cline { 2 - 4 } & $\mathrm{C} 2$ & 0.428 & 0.438 \\
\cline { 2 - 4 } & $\mathrm{C} 3$ & 0.404 & 0.464 \\
\hline \multirow{3}{*}{ Negative Emotion } & $\mathrm{C} 1$ & -0.329 & -0.388 \\
\cline { 2 - 4 } & $\mathrm{C} 2$ & -0.707 & -0.590 \\
\cline { 2 - 4 } & $\mathrm{C} 3$ & -0.477 & -0.693 \\
\hline
\end{tabular}

The results indicate a direct relationship between the teaching content and students' emotion. It is clearly noted that students are interested in interactive teaching content, which they show positive emotions. It figure out that science students and arts students show different feelings and emotions to the same teaching content. Science students have expressed a deep interest in digital game, while arts students might prefer a more interactive activity.

\section{Conclusion}

In this paper, the architecture of e-learning system is proposed based on management of students' emotion. It is aimed at improving the efficiency of students' learning in e-learning system. We design a method based on Kansei Engineering to study the relationship of students' emotions and teaching content. The results of our research figure out that both science students and arts students show deep interesting in interactive teaching content. Furthermore, the novel architecture and research mothed proposed in this paper will be applied in teaching and learning for e-learning system.

\section{References}

[1] W. Westera: Towards multimodal emotion recognition in e-learning environments, Interactive Learning Environments, Vol.24 (2016).

[2] M. Bakaev, M. Gaedke, V. Khvorostov and S. Heil: Extending kansei engineering for requirements consideration in web interaction design, Lecture Notes in Computer Science, (2016) p.513-518.

[3] A. M. Lokman: Design \& Emotion: The Kansei Engineering Methodology, Vol.1 (2010) No.1, p.1-14.

[4] P. Desmet: Measuring emotion: Development and application of an instrument to measure emotional responses to products, Funology (2005) p.111-123.

[5] L. Sheugh and S. H. Alizadeh: A note on pearson correlation coefficient as a metric of similarity in recommender system, Ai \& Robotics (2015) p.1-6. 
[6] B. Bannan-Ritland: Computer-Mediated Communication, eLearning, and Interactivity: A Review of the Research, Quarterly Review of Distance Education, Vol.3 (2002) No.3, p.161-79.

[7] E. Chris and S. Khaled: Evaluation of the interactivity of web-based learning systems: principles and process, Innovations in Education \& Teaching International, Vol.40 (2003) No.1, p.89-99.

[8] N. Kerimbayev, A. Akramova and J. Suleimenova: E-learning for ungraded schools of kazakhstan: experience, implementation, and innovation, Education and Information Technologies, Vol.21 (2016) No.2, p.443-451.

[9] D. K. Viswanath: Cloud Computing Issues and Benefits Modern Education, Global Journal of Computer Science \& Technology (2012).

[10] P. Pocatilu, F. Alecu and M. Vetrici: Measuring the efficiency of cloud computing for e-learning systems, Wseas Transactions on Computers Vol.9 (2010) No.1, p.42-51.

[11] M. W. Allen: Michael allen's guide to e-learning: building interactive, fun, and effective learning programs for any company, Wiley (2016).

[12] P. Kalagiakos and P. Karampelas: Cloud Computing learning, International Conference on Application of Information and Communication Technologies (2011) p.1-4.

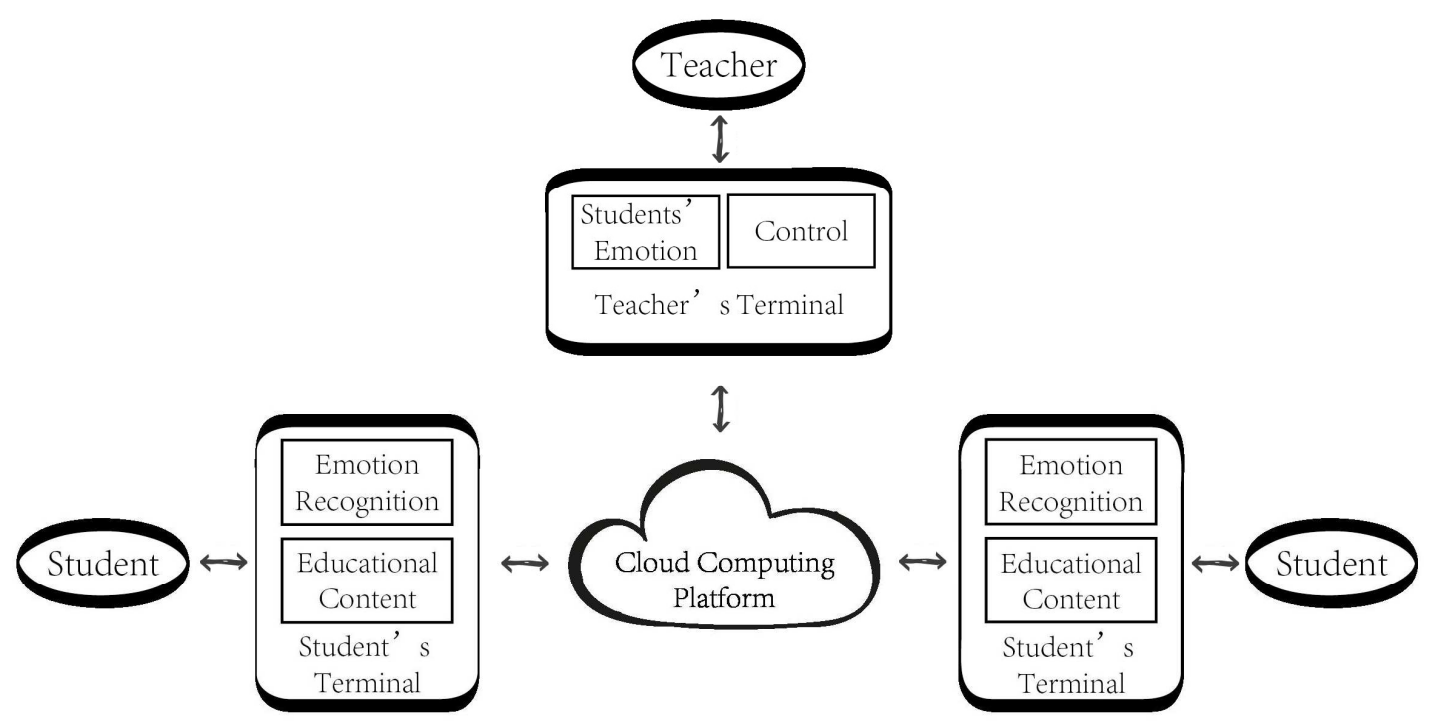

Figure 1. The architecture of our proposed e-learning system 